DESIGN TRADEOFFS FOR A MULTISPECTRAL LINEAR ARRAY (MLA) INSTRUMENT

Aram M. Mika
Santa Rarbara Research Center, Goleta, CA

Abstract

The heart of the MLA design problem is co develop an instrument conced which concurrent1y provides a wide field-of-view with hiah resolution, spectral separation with orecise band-to band reaistration, and excellent radiometric accuracy. often, these requirements have conflicting design implications which can only be resolved by careful tradeof $f$ that consider performance. cost, fabrication feasibility and development risk. The key design tradeoffs for an MLA instrument are addressed in this paper, and elements of a baseline.
instrument concept are presented.

\title{
Background
}

The NASA Landsat program has been thoroughly successful to date, based on the imagery produced by the Multispectzal Scanner. Currently. with spacecraft integration underway for the Thematic Mapper protofliqht instrument, the second generation of Landsat is aporoaching fruition. In light of these developments, the design ohallenge for a third-oeneration MLA sensor is to conceive an instrument that will provide extraordinary beriefits that are well worth the development cost.

The strength of the MLA concept emanates from the pushbroom image-formation aporoach, which offers some fundamental improvements over opto-mechanically scanned instruments." A dramatic advantage of the MLA sensor is the increased dwell time that can be used to inprove signal-to-noise. spectral resolution and spatial resolution simultaneously. The desiqn the spatial resolute parameters is such that only the optical blur circle need constrain the spatial resolution. Thus, an outstanding optical desian is required to exploit the pushbroom approach. However, hlaher resolution by itself is a modest fustiflcation for a new development program. To fully realize the potential benefits of the mua concept. the instrument design must be mechanically simple. with a minimal numbar of movina rarts. Otherwise, the promised reliability advantage of the pushbroom approach may not be achieved.

Moreover, the instrument must provide excellent spatial (band-to-hand) regibtration and radiometric accuracy, as well as minimum geometric distortion. Spectral reqistration and geometric fidelity are essential for accurate color-composite imaqery. object-space reaistration is also extremely important jor successful crop assessment and ciassification, since the precise =adiometric accurac: requized for this task is significantly degraded by alsreaistration. That is, radiometric performance and band-to-band registration are cross-coupled. With inherent band-to-band registration at the instrument, a large seqment of the user community might be served by data that come directly from the spacecraft, or with a minimal amoune of expensive and time-consuming ground processing that delays delivery of data to the customer. This capability is pivotal for many applications, such as crop-yield assessment or evaluation of transient-pollution phenomena, where the utility of Landsat data declines
sharply with time.

Quantitative performance goals have been established for MLA by the NASA Goddard Soace Flight Center, which has been guiting MLA design studies at several companies, including SBRC. 1 These design objectives, summarized in rable 1, serve as a point of departure for the tradeoffs discussed in the following section.

Table 1. MLA Desian Obiectives

\begin{tabular}{|c|c|c|c|c|c|c|}
\hline \multicolumn{2}{|c|}{$\begin{array}{c}\text { Spectral Bands } \\
(1 \pi)\end{array}$} & \multirow{2}{*}{$\begin{array}{c}\begin{array}{c}\text { IFOV } \\
(\pi)\end{array} \\
10-15 \\
10-15 \\
10-15 \\
10-15 \\
20-30 \\
20-30\end{array}$} & \multirow{2}{*}{$\begin{array}{c}\text { SNR } \\
(\mathrm{min}) \\
73 \\
149 \\
126 \\
158 \\
54 \\
77 \\
\end{array}$} & \multirow{2}{*}{$\begin{array}{c}\text { MTE } \\
>0.30 \\
>0.30 \\
>0.30 \\
>0.30 \\
>0.30 \\
>0.30\end{array}$} & Field-of-view & $\begin{array}{l}15^{\circ} \text { Cross-Track } \\
i+20 \text { IFOV In-Irack }\end{array}$ \\
\hline $\begin{array}{l}1.0 .45 \\
2.0 .52 \\
3.0 .63 \\
4.0 .76 \\
5.1 .55 \\
6.2 .08 \\
\end{array}$ & $\begin{array}{l}-0.52 \\
=0.60 \\
=0.69 \\
=0.90 \\
=1.75 \\
=2.35 \\
\end{array}$ & & & & \multirow[t]{2}{*}{$\begin{array}{l}\text { Spectral-pand } \\
\text { Registration }\end{array}$} & \multirow[t]{2}{*}{ 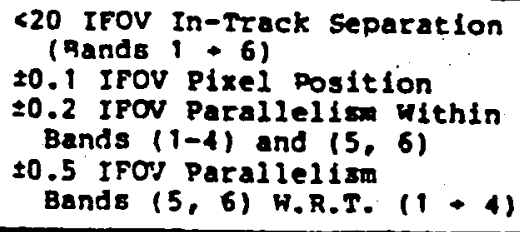 } \\
\hline \multirow{2}{*}{ Notes: } & \multirow{2}{*}{\multicolumn{3}{|c|}{$\begin{array}{l}\text { A. Detector Ifov at } 705 \\
\text { Altitude } \\
\text { B. At Nyquist Frequency }\end{array}$}} & & & \\
\hline & & & & & Pointing modes & $\begin{array}{l} \pm 30^{\circ} \text { Cross-Track } \\
0, \pm 26^{\circ} \text { In-Track (Stereo) }\end{array}$ \\
\hline
\end{tabular}


Table 9. MLA Desian Objecrives (Continued)

\begin{tabular}{|c|c|}
\hline RADIOMETRIC ACCURACY & $\begin{array}{l}\text { 5. ABSOLUTE W.R.T. NBS STANDARDS } \\
\pm 11 \text { RELATIVE INTERBAND } \\
\pm 0.58 \text { RELATIVE INTRABAND }\end{array}$ \\
\hline DATA COMMUNICATION & $\begin{array}{l}2 \times 150 \text { MBPS VIA TDRSS } \\
1 \times 100 \text { MBPS DIRECT DOWNLINR }\end{array}$ \\
\hline SPACECRAFT. INTERPACE & $\begin{array}{l}\text { COMPATIALF, WITH MUTIMISSION SPACECRAFT } \\
\text { (MMS). STS LAUNCH }\end{array}$ \\
\hline
\end{tabular}

\section{Design tradeoffs}

The system-level tradeoffs, which translate mission requirements into a baseline instrument configuration, establish the basic jesian parameters and desian philosophy for the mLA instrument. The heart of the MLA design problem is to develop a desian approach that embodies the following features:

1. Wide field-of-view with high resolution

2. Spectral separation and precise band-to-band reqistration

3. Stereo and cross-track pointing nodes

4. Radiometric accuracy

5. On-board signal/data processinq

6. High rellability - minimum number of moving parts.

Any one of these objectives might be straightforward to attain, but it is challengling to provide all these features in a single instrument, because these requirements have conflicting and interdependent design implications. For example, the optical design strongly influences the spectral separation-registration technique, the stereo/cross-track pointing method and the design of the on-board calibration source. Before deluing lnto the detalls of these hardware tradeoffs, we shall begin by presenting the first-order sizing parameters for the instrument.

\section{Instrument sizing}

Detector pitch, optical focal length, aperture size and intearation time are the basic parameters that determine the ohysical size and radiometrlc performance of the- instrument. These numbers follow directly from the IFOV, MTF and SNR speciflcations. Since detector technology is the dominant feasibility driver for the MLA instrument, detector size and density constraints are a good place to beqin the sizing analysis. For a qiven qround-sampling interval and IFOV, the focal length (and instrument size and cost) is reduced in direct proportion with detector pitch and size. Although SNR is degraded as detector size is decreased, this is not a diving constraint on MLA where anple dwell time is available to build SNR. Therefore, the smallest detector size and pitch, consistent with acceptable processing yield and cost, are desirable for MLA.

Once the optimal detector pitch is selected, the focal length is immeriately determined from IFov and sampling interval requirements. Then, the optical aperture size land hence f-number) is chosen to meet MTF and SNR requirements. This instrument-sizing procedure is illustrated in Figure 1. These sizing tradeoffs lead to an instrument with 12 um square detectors on $15 \mathrm{um}$ centers (bands 1 to 4 , $705 \mathrm{~mm}$ focal length, a $190.5 \mathrm{~mm}$ aperture diame$t e r$, and other parameters as shown in Table 2. Additionally, the 705 min focal length yields a fortuitous relationship between dimensions on the ground and on the focal plane: im on the ground corresponds to 1 um on the focal plane (for the $705 \mathrm{~km}$ orblt).

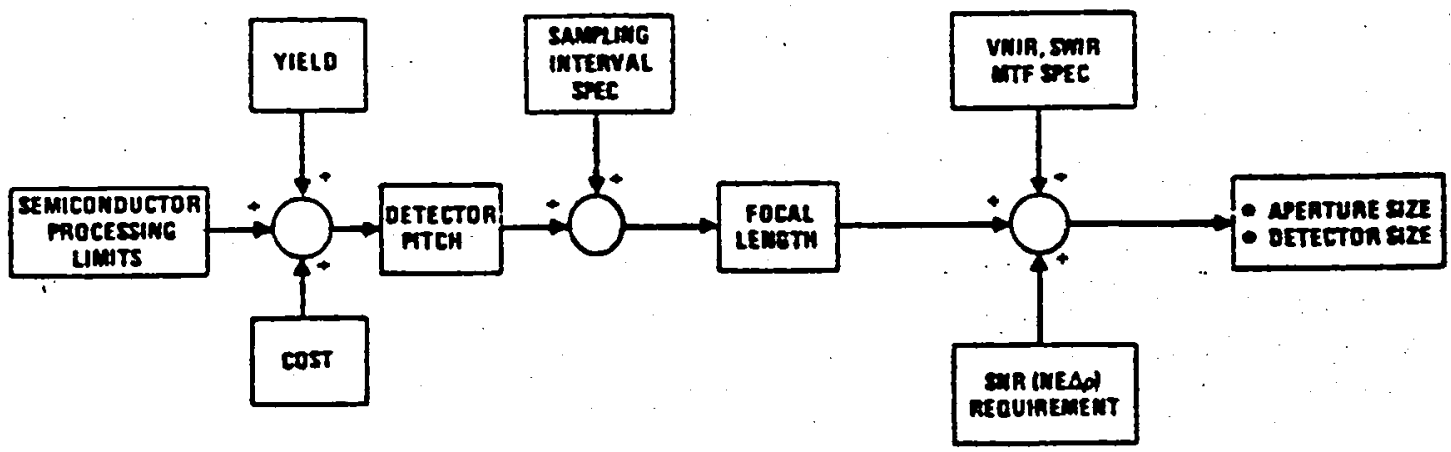

Figure 1. Instrument sizing procedura 
Table 2. System Paraneter sumary

\begin{tabular}{|l|l|}
\hline Aperture Diameter & $190.5 \mathrm{~mm}$ \\
focal fength & $705 \mathrm{~mm}$ \\
f/No. & 3.7 \\
Ifov at $705 \mathrm{~km}$ & $12 \mathrm{~m}(17.0 \mathrm{urad})$ Bands, 4 \\
& $25 \mathrm{~m}(35.5$ urad) Bands 5,6 \\
Sampling Interval & $15 \mathrm{~m}(21.3 \mathrm{urad})$ Sands \\
& $30 \mathrm{~m}(42.6 \mathrm{urad})$ Bands 5,6 \\
Vumber of Detectors & 61,440 \\
Data Rate (Uncompressed) & $208-570$ Mrps \\
\hline
\end{tabular}

\section{Configuration tradeoffs}

The sizing parameters establisher above set the staqe for confiauration trateoffs. This section summarizes the nrincioal packaqina consiterations, iJentifies the most oromising candidate, and presents the rationale for that selection.

The overall instrument confiauration appears to be most stronaly influencen by the

following factors, listed in the order of their importance to the selection process:

1. Stereo mode implementation

2. Cross-track mote implementation

3. Radiative cooler tield-of-view

4. Spacecraft structural inteqration

Three generic configurations are possible, with optical systems whose princioal axes are oriented along the orbital track, cross track, and narir directions. Figure 2 illustrates these alternatives, and the relative merits and flaws of each aporoach are also noted in the Eigure.

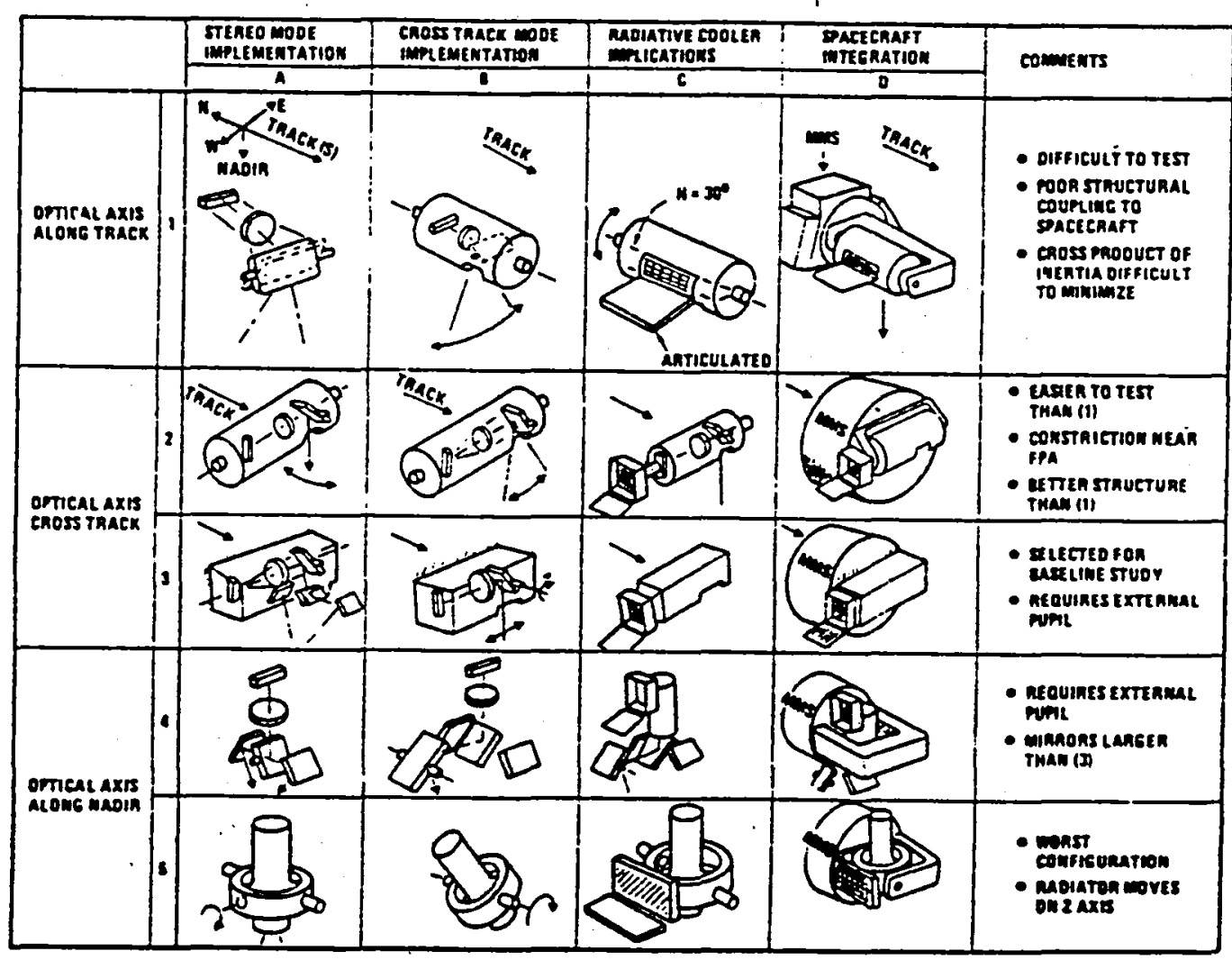

fiqure 2. Confíquration tradeoffs 
Confiquration number three (with the oftical axis in the cross-track airection), when coupled with an optical design havina a convenient entrance-pupil location, was selecter. This configuration provides an excellent combination of simpilicity and compactness: articulated radiators, rotating sensors, oversized mirrors and other undesirable features are absent.

\section{Optital desian tradeoffs}

Performence requirements in the areas of pointing capability, field of view (Fov). resolution, spectral coverage, radiometric accuracy and spectral reqistration are hiahly coupled and contain important implications for the MLA optical form. As oresented in Table 3 , a variety of additional optical system characteristics strongly affect the design of other uLA subsystems. For example, a flat foca! olane will greatly facilitate detector-array assembly and alignment. The use of relayed optical form will improve stray light rejection and simplify on-orbit detector calibration. The optical form should permit compact system packagina consistent with MMS payload capabilities, and fabrication and alignment tolerances must be realistic in order to guarantee satisfactory on-orbit optical-system resolution. An unobscured system with adequate performance margin will simplify scaling to sensors with improved resolution, and an all-reflective telescope will permit future inclusion of LhIR spectral bands. Minimal geometric distortion.will reduce post-processing reguirements for some applications. Finally, telecentridity normal incidence for all chief rays in the field of view) is an extremely important feeture, since it eliminates angular variations in coating performance (for dichroic and spectral-bandpass filters).

$$
\text { Table 3. MLA Optical System Desired Characteristics }
$$

\begin{tabular}{|c|c|}
\hline Desized Feature & Motivation \\
\hline $\begin{array}{l}\text { Flat Focal Plane } \\
\text { Telecentricity } \\
\text { Pelayed optical Form } \\
\text { Real Entrance Plipil } \\
\text { Unobscured Aperture } \\
\text { Compazt Packaging } \\
\text { Feasible Optical System } \\
\text { Tolerances } \\
\text { Aly-Reflective Telescope } \\
\text { Performance Margin } \\
\text { Minimal Geometric } \\
\text { Distortion }\end{array}$ & $\begin{array}{l}\text { Simplified alignment and assembly for FPA detectors } \\
\text { Low focal plane anqles of incidence, simplified } \\
\text { spectral sedaration, uniform filer performance } \\
\text { Intermediate image: simplified on-orbit cal-ibration } \\
\text { and stray light rejection } \\
\text { Reduced stereo mirror size } \\
\text { Improved optics MTF } \\
\text { Maintain compatibility with MMS } \\
\text { Simplify sensor integration, reduce risk } \\
\text { Lwr growth capability } \\
\text { Simplify scaling to lom/20m system } \\
\text { Reduced post-processing requirements }\end{array}$ \\
\hline
\end{tabular}

A variety of telescope design forms have been considered for use in the MLA sensor. These optical desiqns have been evaluated against the set of performance requirements and desired features listed above. The design form options considered for mLA are depicted in figure 3. The various schmidt designs and the four-mirror telecentric system are the principal oesign candidates. However, the schmidt approaches have serious flaws ranqina from non-telecentricity and curved focal surfaces (for some variants) to unfavorable pupil locations and intractable pointing-mirror sizes. For a complete exposition of the key tradeoff issues, the reader is directed to Reference 2:

The four-mirror telecentric design (Figure 3.1-5c) has been selected as the MLA optical system baseline because of its excellent combination of optical performance and desirable features. Main advantages of this form are its real entrance pubil, intermediate image, flat focal plane, and telecentricity. The folded version of this telescope provides compact packaging, and image quality $(10-12$ usad 80 blur diameter in band 3$)$ is better than MuA specifications. Moreover, this all-reflective design has an unobscured aperture. Although the as-designed optical perfcrmance of this system is outstanding, fabrication feasibility, al ianment sensitivity and on-orbit alignment stability are also important. Each of these issues has been addressed in depth, as discussed in Reference 2. This work has shown that the four-mirror telecentric system is a thoroughly workable design for MuA. Fughes has demonstrated (with hardware) a similar four-mirror system with off-axis aspheric elements, and the measured performance of this system is as predicted for the design. A key factor in achleving the designed performance for these systems is a Hugtes-developed computer-aided optical alignment method wich ensures optimal alignment of the mirrors and permits relaxation of Eigure tolerances. 


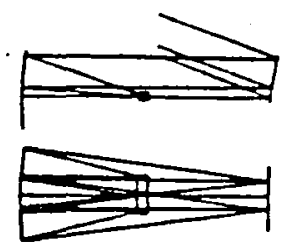

a) REFIECTING SCMMIDT

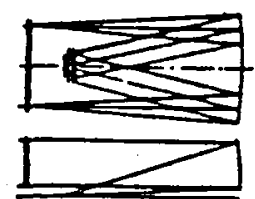

U SHOAT, FLAT-FIELO SCHAMOT

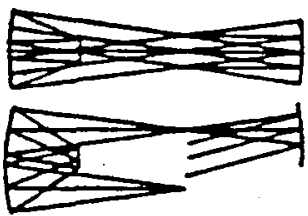

d Foundahon tececentar

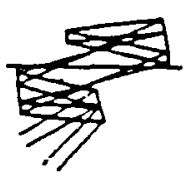

d) wal Rus

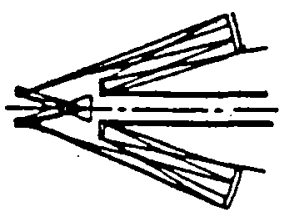

e) AETAOCENTAIC (SCHWARTZCHILO)

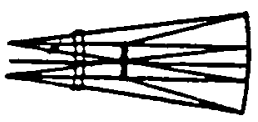

f couneas concentaie

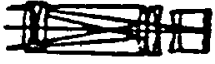

c HTRAL

Figure 3. Telescope desion alternatives

Spectral separation and reqistration

The requirements for spectral separation and band-to-band reqistration are sianificant considerations for the MLA instrument. The spectral-separation approach has imolications that ripple through the system, in the areas of optical design, detector packaina, coolina, structural design and signal/data processing.

Two fundamental points of departure for selecting a spectral-separation approach hinge on the desirability of naintaining true object-space reqistration and on the location of the visible-near infrared (VNIR) and short-wave infrared (SWIR) focal Dlanes. The key tradeoff in achieving soectral rejistration centers on how the detectors are mounter. The mounting of the detectors is affected by the choice between the two different philosophies for reaistration of the MLA bands; time delay between darallel rows of detectors or soectral beamsplitting of the incoming enerqy.

The time-delay approach leads to a misreqistration of 0.2 Ifov at the edge of the fleld of view, even with ideal (constant focal length) ootics. Thus, obiect-space reqistration is not achieved, and extensive corrective data processing would be required to produce the registered imaqery needed for many applications. Therefore, a heamsolitter utilizina dichroic filters has been selected, as illustrated in fiqure 4. This approach provides coincident images in all six bands.

The preferrei tilter-plate beamsplitter aporodch leads to the next major tradeoff; to mount all the detectors on a common substrate and cool the entire assenbiy or to cool only the two SWIK bands. If only the SWIR bands are cooled then they must be reaistered with an ultra-low hysteresis nount or servoed into a position of reaistration with the visible Hetectors. Cross-track registration becomes another issue because the cooled detectors may have a coefficient of expansion that is larae enough to misregister detectors along the length of the array relative to the corresponding warm VNIR arrays. For these and other reasons it appears that cooling all the detectors on a comon, isothermal substrate minimizes misregistration due to structural compliance and differential thermal effects.

\section{Radiometric accuracy and calibration tradeoffs}

Achieving the required radiometric precision for mis raises several important issues regarding dotectors, signal-processing, and callbration approach. Wuch of the radionetricaccuracy issue hinges on the performance of the detectors, particularly for the SwIR hands, so this is a good place to begin the discussion. The detector material ond temperature directly afect radionetric performance because responsivity and $1 / 6$ nolse (which are naterial and temperature dependent) influence SNR and calsbration frequency. Moreover, the selection of a SWIR detector material is tightly coupler to other asoects of the instrument design. since the operating-temperature requirements influence the cooler size, mechantcal layout ant spectral-realetration approach. 


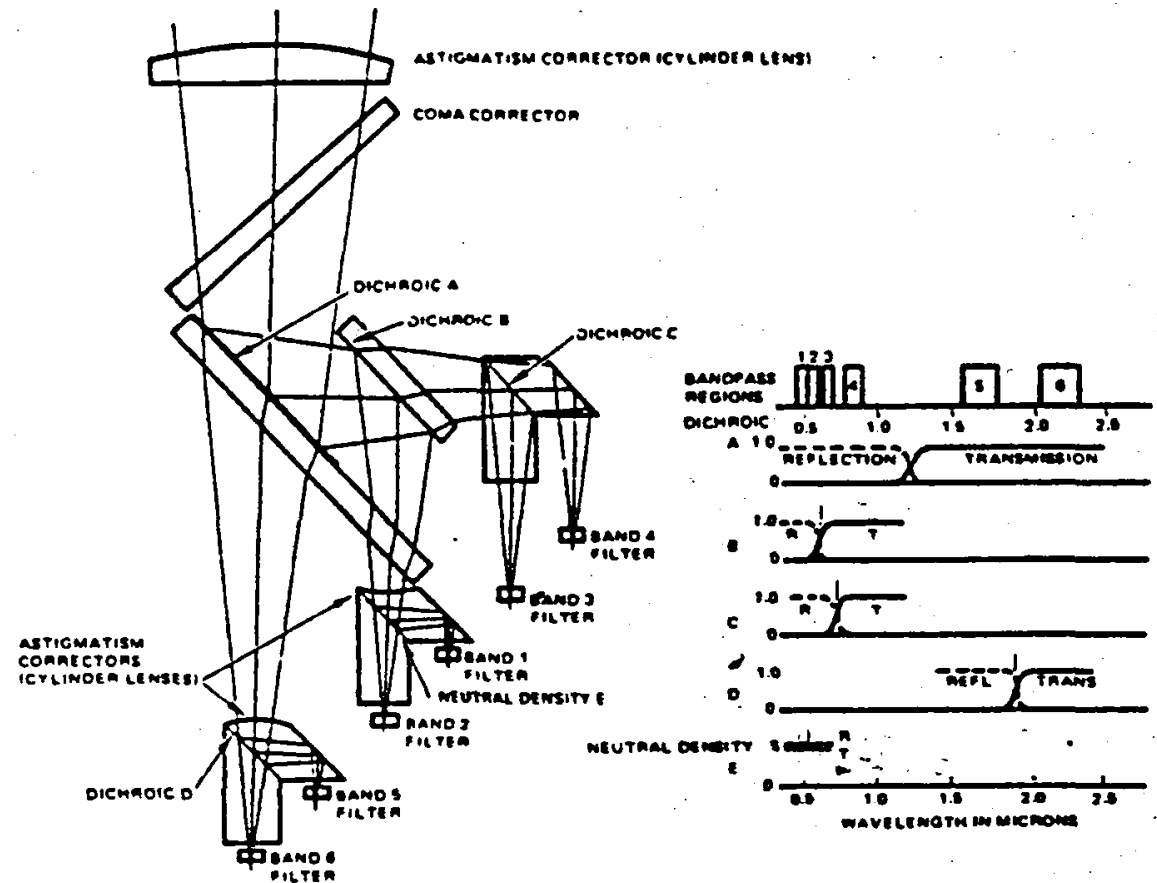

Flqure 4. Beansplitter concept

The preferzed spectral-separation/registration approach, with a six-band colocatd, 1sothermal focal-plane assembly, poses some temperature restrictions, if reasonably-sized radiative coolers are employed. Specifically, a complete six-band focal-plane assenbly requiras on the order or 5 of cooling capacity. including the parasitic heat loads due to cables. supporting structures, and the like. With a tractably-sized ranlator, say with an area of $0.2 \mathrm{~m}^{2}$, focal-plane temperatures as low as $155 \mathrm{~K}$ are achievable. In this operating-tenperature regime, the detector material of choice is Hgcate. palladium silicide another candidate detector material, requires a much lower, temperature (circa 110K) and has poor responsivity. However, if the $\mathrm{l} / \mathrm{f}$ nolse properties of HgCdTe introduce radioaetric-drift errors that must be corrected by frequent. recalibration - or even a chopper assembly - then the attractiveness of the isothermal-FPA approach and HgCdTe SWIR detectors comes into question.

The crux of this issue is the potential requirenent for an opto-mechanical chopper. Incorporating a chopper would violate the no-moving-parts design ohilosophy of qua. imile an MLA instrument without a chopper would still have movable pointina mirrors, the fundamental imaging operation of the instrument would not depend on any rotaring or oscillatina components. Indeed, if a chopper were necessary, the entire issue of a scanned versus pushbroom instrument would merit reexamination, since the perceived reliability advantade of the pustibroom design might be eliminated. In addition to the severe reliability issue inclusion of a chopper would reduce SNR in proportión to the effective transmission loss caused by periodic blanking of the decectors.

In view of the pivotal nature of this issue, a compehensive analysis of arife and $1 / E$ noise was undertaken. This analysis was verifled by measured data, and the results of this work indicate that drift in the SWIR (as well as the ViIR) bands will be less than 0.05 of tull scaie during an orbital oerlod when Hacdie detectors are operated at 175R. This irift level is well within the GSFC radiometric-accuracy specification. The predicted irift is also well below the even more stringent - 0.2 uniformity required to avold cosintic defects (striping) in the imagery. Thus, chopper mechanism is unneceseary.

other tradeoffs affecting radiometric accuracy, including the design and location of calibration sources, the precision of $\mathrm{A} / \mathrm{D}$ quantization and subsequent on-board calibration correction, have also been addressed.

\section{Instrument concept}

The design tradeoffs outlined above heve led to the Instrument concept illustrated In Figure 5. This flgure is a photograph of full-scale nockup fabricated at 5BRe as an aid tor visualizing the key elements of the inatrument. Figure 5, which is a cutaway Arawlng 
corresponding to the mockup photo, reveals the internal details of the sensor. The mockup does not show the instruments' covers or stereo mirror module, and these adnitional items are depicted in Figure 7 .
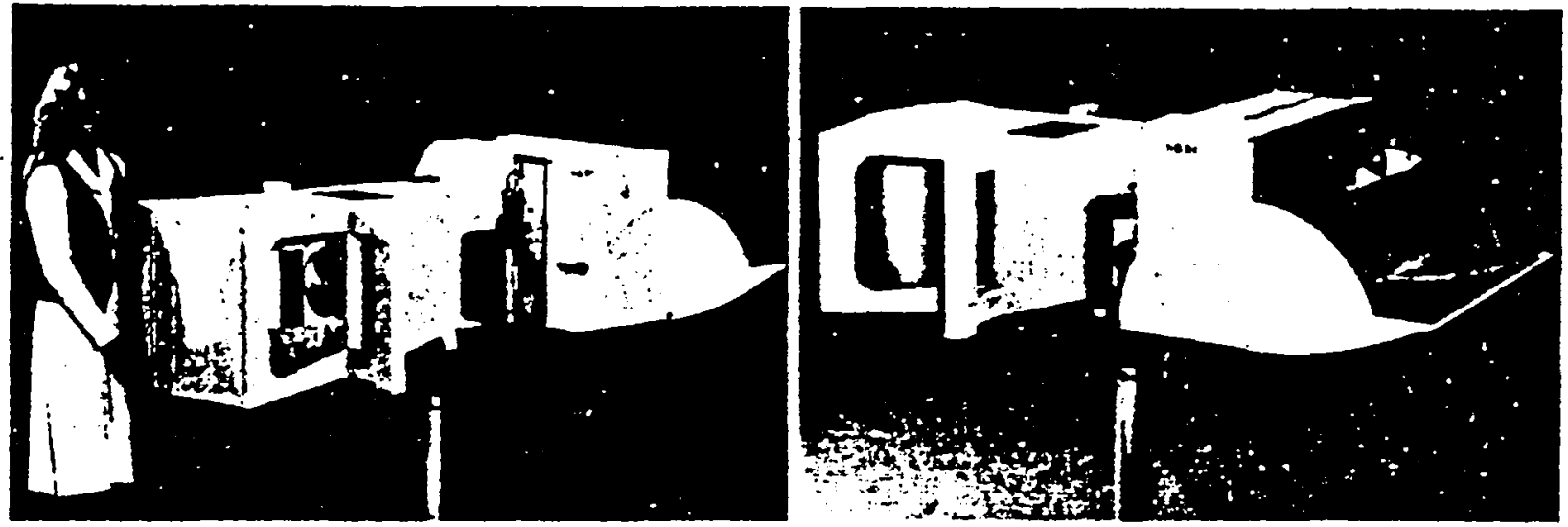

Flgure 5. Multi-spectral linear array (MLA) instrument full-scale mock-up

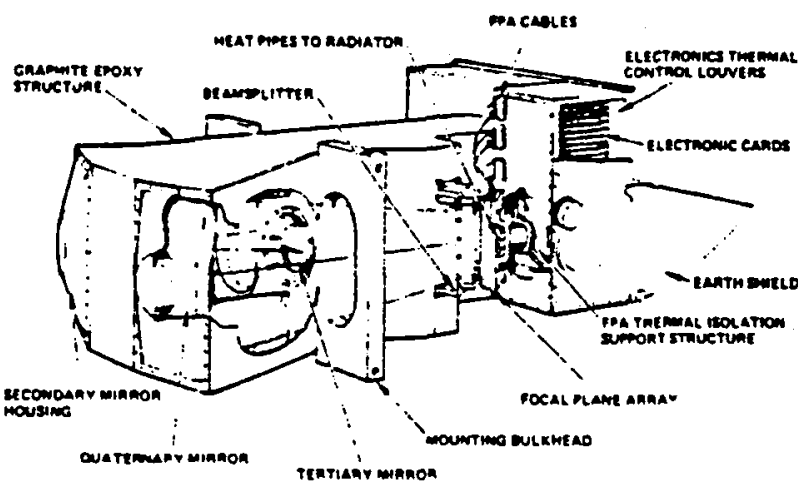

Figure 6. MLA instrument cutaway view

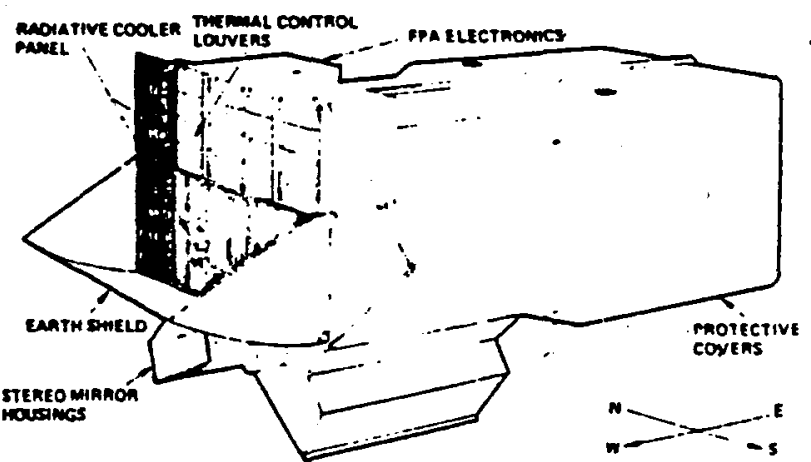

Fiqure 7. MLA instrument with covers and stereo module

The telescope and beamsplitter have been described in the preceding section; highlights of other subsystems are presented below.

\section{Focal plane assembly}

The baseline focal-plane design consists of six color bands arranqed in stairstep fashion as dictated by the beansplitter design. The focal plane is modular at the band level, with each assembly electrically independent of the others, as illustrated in Fiqure 8 . thus, the band assemblies can be functionally tested separately and in parallel. with special tooling, the detector modules are precisely located on substrate, and these completed band assemblies in turn mount to a monolithic staircase structure which has diamond-machined mounting surfaces that provide the required positioninq accuracy for the detactor arrays. The staircase is thermaliy coupled to the radiative cooler via two redundant heat pipes. Although the focal-plane temperature is controlled at 175k, the cooler has sufficient design margin to achieve temperatures as low as $155 K$ with the nominal $5 w$ total heat load, as discussed earlier.

On the focal plane, hands 1 through 4 employ silicon photodiodes, while Hacate photoriodes are used for bands 5 and 6 . The two SWIR detector arrays esch consist of 6,144 detectors, and the four VNIR detector arrays each have 12,288 detectors. Each of the $\mathrm{six}$ bandlevel assemblies are composed of precisely-butted modules. To read out all the more than 60,000 detector signals, each module has a corresponding multiplexer (mux). In the VNIR bands, the mux and detector array are monolithic unit. In the swIR bands, a hybrid structure is used: HgCdTe ietectors with silicon nox chip. 


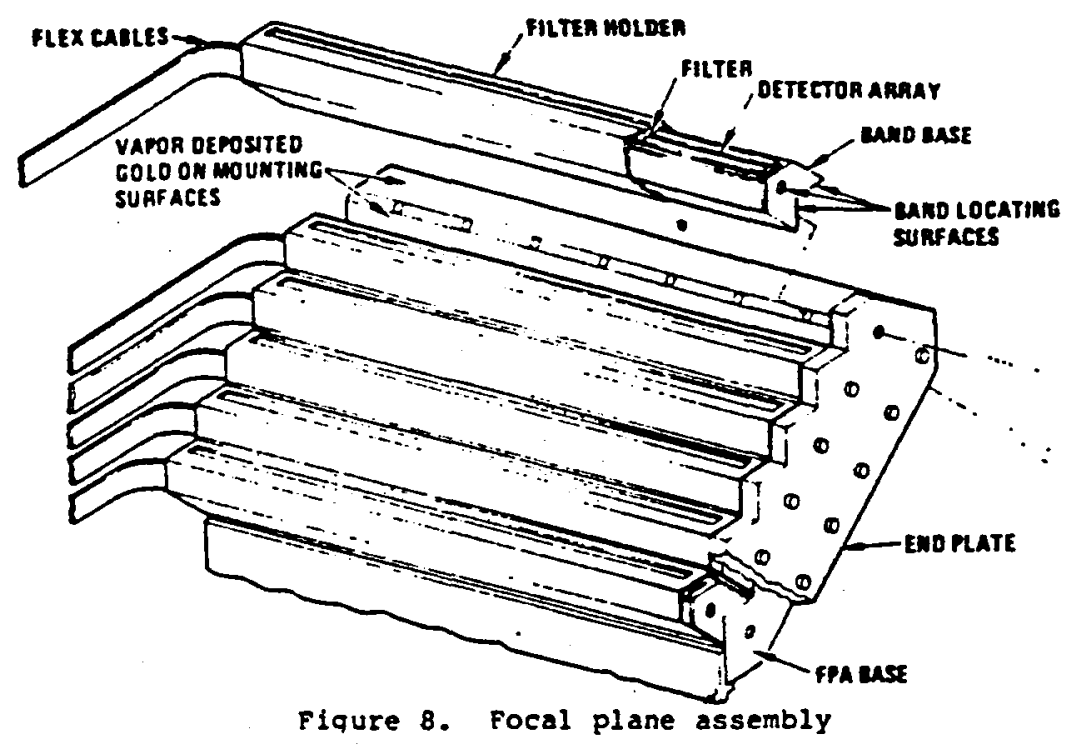

\section{Electronics}

The existence of a large array of detectors and simultaneous sianal output fron many modules pose significant problems in signal processing, such as speed and reliability. An attractive solution is a hiahly distributed hardware design, involving many redicated electronic systems working in parallel. For the purposes of signal processing, the focal plane was organized into 48 sections, or "slices," each containing its own independent processing chain. Each slice consists of the aforementioned output multiplexing devices, as well as associated analog-to-digital converters, and digital signal processinq circuits. This distributed approach is the key to meeting reliability objectives while fulfilling the highspeed signal-processing requirements for MLA. The architecture provides additional benefits in terms of low power dissipation with correspondingly simple thermal control: Moreover, the parallel approach yields thoroughly tractable data rates through the signal-processing chain illustrated in Fiqure 9.

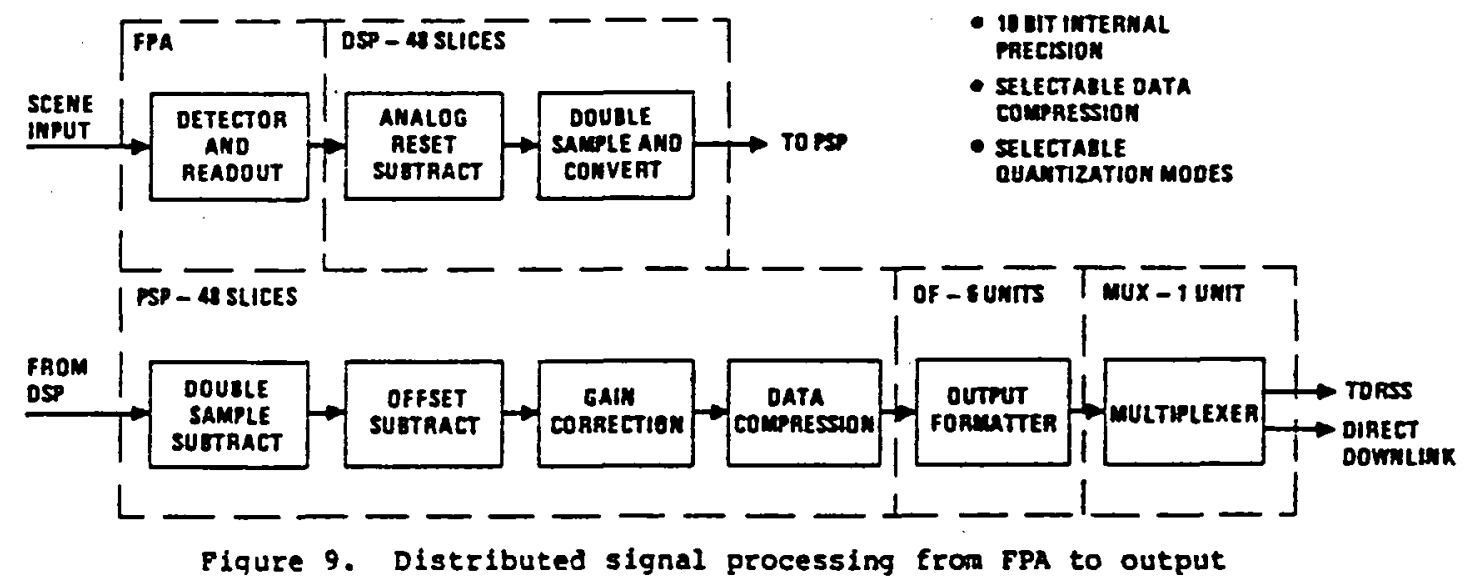

The processing starts at the FPA, with the first-level multiplexing. Under the supervision of ten timing and concrol (TC) circuits, all 48 FPA slices are processed simultaneous1y. From the FPA, signals enter the detector siqnal processor (DSP), where ten-bit A/D conversion is performed in an interleaved fashion that obviates the need for buffer memory. Under microprogram control, the DSP/TC provides the variable-rate timing for different orbits.

The Algital sianals from the DSP can be transmitted uncompressed at full ten-bit resolution from the $705 \mathrm{~km}$ orbit. However, at the lower orbits (283 and $470 \mathrm{~km})$, the short detector sample time learis to data rates that exceed IDRSS capacity. Therefore, in andition to detector qain and offset correction, the proqrammable siọnal processor (PSP) provides data compression. Selectable compression morles include standard differential pulse core moruja$t$ ion (DPCM) as well as a Huahes-developed advanced DPCY (ADPCM), which combines OPCM with a 
predictive coder. ADPCM will provide lossless data compression for aany scenes. Various quantization modes are avaliable which take advantage of the ten-bit $A / 0$ converter orecision. Fr example, one mode allows increased precision over a reduced dynasic range. From the PSP, the 2.3 to $5.3 \mathrm{MHz}$ parallel data (depending on the orbit) enter the output formatter where they are organized for serial transmission. Additionally, there is a command processor which orchestrates control and telemetry for the entire instrument.

\section{On-board calibration}

The on-board calibration concept includes a controlled callbration source at the intermediate image plane between the folding airror and the secondary mirror, movable solar diffuser that can be positioned in front of the entrance pupil, and a backup collimator located within the stereo-mirror module. The location of the source allows for system calibration from the secondary mirror to the video output, while the solar diffuser provides an end-toend calibration reference that also encomasses the mirrors that precede the controlled calibration source. However, the reflectance properties of these mirrors will change slow$1 y$, so relatively-infrequent solar calibration will be adequate.

The principal on-board calibrator is a cylindrical inteqrating source (CIS), which consists of a metal cavity with thirty incandescent lamps distributed along the length of the cylinder. The interior of the cavity. which has a diffuse surface coating, serves to average or "integrate" the lamp 111 umination. So that nearly uniform radiance appears at the exit slit. During calibration, the folling mirror near the intermediate image plane is rotated so that the CIS illuminates the focal-plane assembly (FPA). A closed-loop siliconphotodiode sensor circuit controls the cIs at six distrete ilght levels, which are obtained by activating different numbers of lamps.

\section{Summary}

The principal design tradeoffs for an MLA instrument encompass the opto-wechanical layout, spectral separation/registration approach, detector selection and siqnal-processinq architecture. These tradeoffs led to an instrument concept employina a four-mirror-telecentric telescope, coupled with a six-way beamsplitter, an isothermal focal-plane assembiy and highly distributed signal processing. Rey features of the concept include object-space registration of all six spectral bands, stereo and cross-track pointing via conpact mirrors. and a small overall envelope compatible with the multimission spacecraft.

\section{Acknowledgements}

The MLA instrument study represents the cooperative effort of over forty Deople at Hughes/SBRC, as listed below, and it. is. this collective work that has been suimmarized in the preceding paper. The work reported here was supported in part by NaSA Contract No. NAS526591 , under the technical direction of $\mathrm{Mr}$. H.L. Rlchard of the Goddard Space Flight Center.

MLA Study Contributors

Cliff Adams
Ray Amador
Gary Barnett
Ron Blumenthal
Steve Botts
Jack Brooks
Elliot Burke
Terry Cafferty
Dick Chandos
Art Chapman
Still Chase
Dick Cline

Cliff Adams Gary Barnett Steve Botts Jack Brooks Terry Cafferty

Art Chapman

Dick cline

Brian Cohn
Lacy Cook
Bob Cooley
Loren Criss
Roland Davis
Brent Ellerbroek
Donna Evett
Brent Frogget
Steve Gaalema
Fred Gallaghe:
Ellen Gerardis
George Fershman

Jim Hesson
Dave Hi=zelberg̣er
Roger Hoelter
Ron Rimmel
Jim Rodak
Lisa Krone-Schmidt
Jack iansina
Dana Horrison
Virginia Norwood
Smitty Preston
Jim Randolph
Cesar Rodil

Dave $H i=z e l b e r g e r$

Roger Hoelter

Lisa krone-schmidt

Jack iansina

virginia Norwood

$J$ in Randolph

Cesar Rodil
Tony Schoepke Carl schueler Ren Shamordola George Speake Irv Sperling Rich Thom Robert Turtle Bert Karren Milt Waxman Roger Withrington $J$ if Young

\section{References}

1. H.L. Richard, "Solid state Instrumentation Concepts For Earth Resource Observation. Proceedings of the Twentieth Goddard Menorial Symposium, Greenbelt, Maryland, Mmerican Astronautical Society, March 1982.

2. Multispectral LInear Array Opticel System Design Study." Santa Barbara Research Center, NASA/GSFC Contract No. NAS5-26591, March 1982. 